\title{
DEFICIÊNCIA EM PERSPECTIVA: RELAÇÕES ENTRE REPRESENTAÇÕES SOCIAIS E ALTERIDADE NA COMUNIDADE DO JARANA NO MUNICÍPIO DE BRAGANÇA-PA
}

\author{
DISCAPACIDAD EN PERSPECTIVA: RELACIONES ENTRE REPRESENTAIONES \\ SOCIALES Y ALTERIDAD EN LA COMUNIDAD DEL JARANA EN LA CIUDAD DE \\ BRAGANCA-PA
}

\section{DISABILITY IN PERSPECTIVE: RELATIONSHIPS BETWEEN SOCIAL REPRESENTATIONS AND ALTERATION IN THE COMMUNITY OF JARANA IN THE MUNICIPALITY OF BRAGANCA-PA}

\author{
Viviane Silva PEREIRA ${ }^{1}$ \\ Ricardo Augusto Gomes PEREIRA ${ }^{2}$ \\ Carlos Jorge PAIXÃO ${ }^{3}$
}

RESUMO: A forma como determinamos o recorte do "outro", tem sido problematizada nos estudos que tem como cenário o meio social. Considerando essa delimitação é que esta pesquisa analisará as relações entre as Representações Sociais e Alteridade do "outro", balizadas pela lente da deficiência. Nesse sentido, o objetivo geral desse estudo é verificar qual(is) a(s) forma(s) assumida(s) pelas representações sociais que estão a frente dos sentidos de alteridade construídos, sob a égide da deficiência, na comunidade de Vila Jarana. Trata-se de um estudo qualitativo, de cunho etnográfico, realizado com um total de 13 estudantes pertencentes à referida comunidade e cujos dados obtidos posteriormente foram entrelaçados aos cernes teóricos. Os resultados deste estudo indicam que as representações sociais, categorizadas pelos estudantes daquela comunidade, no que concerne à concepção de deficiência, conduzem a formulações de alteridade que se assentam em limiares de exclusão. Nesse sentido, a finalização deste artigo aponta para a necessidade de se repensar forma como estão ancoradas as representações sociais que têm conduzido os ajustes sociais da alteridade em relação à deficiência para além de um olhar pacificado, em referenciais dicotômicos e excludentes do outro sob a alcunha da deficiência.

PALAVRAS-CHAVE: Alteridade. Representações sociais. Deficiência.

RESUMEN: La forma por la cual determinamos la imagen del "otro" ha sido problematizada en los estudios que tienen como escenario el medio social. Considerando esta delimitación es que esta investigación analizará las relaciones entre las Representaciones Sociales y Alteridad del "otro", medidas desde la mirada de la discapacidad. En este sentido, el objetivo general de este estudio es verificar cual(es) es(son) la(s) forma(s) asumida(s) por

\footnotetext{
1 Universidade Federal do Pará (UFPA), Belém - PA - Brasil. Mestranda em Educação (PPGED/ICED). ORCID: <https://orcid.org/0000-0003-3761-9520>. E-mail: neoalquimista@gmail.com

2 Universidade Federal do Pará (UFPA), Belém - PA - Brasil. Doutorando em Educação (PPGED/ICED). Mestre em Educação. ORCID: <https://orcid.org/0000-0002-1626-6378>. E-mail: pereiraric19@gmail.com

3 Universidade Federal do Pará (UFPA), Belém - PA - Brasil. Docente do PPGED/ICED. ORCID: <https://orcid.org/0000-0002-4528-9907>. E-mail: carlosjpaixao@ hotmail.com
} 
las representaciones sociales que están delante de los sentidos de alteridad que se han construidos, bajo los auspicios de la discapacidad en la comunidad de Vila Jarana. Se trata de un estudio cualitativo y etnográfico, realizado con el total de 13 estudiantes que pertenecen a la dicha comunidad y cuyos datos obtenidos posteriormente que se han entrelazado por los teóricos centrales. Los resultados de este estudio indican que las representaciones sociales, categorizadas por los estudiantes de la dicha comunidad en lo que respecta a la concepción de la discapacidad, conducen a formulaciones de la alteridad que se basan en las fronteras de la exclusión. En este sentido la finalización de este artículo señala la necesidad de repensarse la manera por la cual están ancoradas las representaciones sociales que han conducido a los arreglos sociales de la alteridad respeto a la discapacidad, más allá de una mirada pacífica, en referenciales dicotómicos y excluyentes del otro bajo el apodo de discapacidad.

PALABRAS CLAVE: Alteridad. Representaciones sociales. Discapacidad.

ABSTRACT: The way we determine the "other" clipping has been problematized in studies in social psychology. Starting from this delimitation, this article will deal with the relationship between the Social Representations and the Otherness of the "other", marked by the lens of the deficiency. In this sense, the general objective of this study is to verify the form (s) assumed by the social representations that are ahead of the meanings of otherness that are built under the aegis of disability in the community of Vila Jarana. This is a qualitative, ethnographic study carried out with a total of 13 students belonging to this community and whose data were subsequently interwoven with the theoretical keys. The results indicate that the social representations, categorized by the students of that community, regarding the concept of disability, lead to formulations of alterity if they are based on exclusion thresholds. In this sense, the conclusion of this article points to the need to rethink how the social representations that have led the social adjustments of the alterity in relation to disability are anchored in addition to a pacified look in dichotomous references and excluding the other under the nickname of disability.

KEYWORDS: Alterity. Social Representations. Deficiency.

\section{Introdução}

As percepções do outro, cuja referência e sentido encontra-se em Jodelet (1998), tem sido objeto de estudo recorrente no campo da Psicologia social, dado que está circunda estudos que visam à compreensão de como as representações sociais podem influenciar sobremaneira a forma como são construídos os laços sociais entre os sujeitos.

Os estudos que contemplam as representações sociais, especificamente as investigações sobre alteridade, nos permitem entender como acontecem as interações a nível intersubjetivo entre o "eu" e o "outro", e de que forma essa relação culmina em mecanismos que se estruturam para qualificar os sujeitos em gradações as quais irão influir em sua substantivação no contexto da sociedade. 
Deste modo, Jodelet (2002), ao se referir à alteridade, percebe-a como uma qualificação que é induzida pelas condições do meio exterior, no plano do vínculo social, atribuídas ao objeto ou sujeito visado. No caso do sujeito, aquele que é entendido como "não eu" ou o "outro" só poderia ser compreendido, no seio da relação social, em torno de padrões de diferença, ou seja, daquilo que é oposto ao "eu" e que se manifesta segundo consulta prévia às representações sociais que referenciam os comportamentos grupais, em sentido geral ou especifico.

A análise, por esse aspecto, implicaria proporcionar a percepção dos degraus e estatutos diversos que promovem as conotações referentes ao outro, as quais se evidenciam por intermédio da formulação de escalas gradativas que vão do "mesmo" ao "outro", proporcionando-se um espectro de diferenciação. O "eu" nesse caso é sempre tomando como referência para tal, ou seja, a autora considera que a alteridade não se compõe de uma característica intrínseca do ser, mas que é definida no âmbito social, haja vista que só encontra sua coerência na caracterização do outro, como oposto àquilo que é considerado próprio da identidade do "eu", nesse termos o "eu" seria o parâmetro de onde partiriam as gradações que definem os outros.

Percebe-se nesse sentido que as representações sociais podem influenciar as escalas de diferenciação do outro até a culminância de sua distinção, por via do processo de construção da alteridade, ou como nos simplifica Carlos Brandão (1985, p. 1): "O diferente é o outro, e o reconhecimento da diferença é a consciência da alteridade". Esse processo, sobre a consciência da alteridade, a que se refere o autor, o qual implica em processos de diferenciação de outrem, também pode contribuir para que determinada representação social seja pacificada por um período maior ou menor de tempo nos grupos sociais.

Dessa forma, as compreensões sobre a alteridade nos dão, em determinada medida, o suporte teórico para desvendar como são formuladas, ou de que forma estas influenciam as próprias representações sociais, quanto à definição e/ou entendimentos sobre temas específicos, como a deficiência, os quais transitam em diversas representações e entre diversos tecidos sociais.

Skillar (1999) pressupõe que a deficiência está imbricada em uma determinada lógica de exclusão, encarnada pelo status de uma alteridade, a qual denominou de alteridade "deficiente", de acordo com o autor, tal configuração é legitimada por um padrão cuja compreensão está assentada na cisão entre o "eu" e os outros deficientes 4 .

${ }^{4}$ Grifos do autor. 
Por meio de tal propositura é possível perceber que na contemporaneidade a deficiência tem sido retratada por meio de uma tendência que se assenta em princípios de natureza segregativa, destarte os estudos sobre a alteridade e representações sociais nos concedem possibilidades de problematizar essa realidade, mas para que se possa fazer determinada análise crítica a esse respeito, faz-se necessário entender a forma como os mecanismos se confabulam em fontes disseminadoras de exclusão, os quais acabam por trazer consequências significativas para aqueles que convivem diariamente nesse limiar.

Para fins deste estudo, definiu-se como lócus de pesquisa a comunidade do Jarana, região rural do município de Bragança-PA, de modo a dar materialidade à discussão proposta no âmbito das vivências, no intuito de apreender: Que formas têm assumido as representações que espelham a alteridade, que tem perpassado as concepções de deficiência dos estudantes da vila Jarana?

A problemática ganhou seus contornos por meio de incursões na comunidade em questão, por meio delas foi possível pensar no recorte desta pesquisa, cuja abrangência está na forma como o outro é condicionado, considerando-se o aspecto da deficiência. A intencionalidade do estudo dessa temática encontra seu fundamento justamente por meio de olhares que se expressam em um contexto social específico, contudo não menos relevantes, no sentido de captar as relações, consonâncias ou dissonâncias com contextos mais amplos, nos quais também se articulam as relações entre representações sociais, alteridade e deficiência. As constatações sobre a forma como foram percebidas as relações entre essas categorias foram demostradas principalmente por meio do diálogo com os sujeitos e apresentadas nos desfechos finais da pesquisa.

Vale considerar, segundo Skillar (1999), que a presunção de deficiência, assentada sob a ótica excludente, necessita ser repensada, visto que acaba se estabelecendo como norma, funcionando muitas vezes como uma espécie de invenção que acaba trazendo implicações diretas na forma como os sujeitos se relacionam uns com os outros, fato que pode incorrer regulações da forma como são pensados e inventados os corpos e mentes dos outros em "condição" de deficiência.

Assim, o objetivo desse artigo é verificar sobre quais sentidos estão assentadas as representações sociais que embasam as concepções sobre deficiência dos alunos da comunidade de Jarana no município de Bragança.

Em vista de alcançar este objetivo optou-se pela pesquisa etnográfica como incursão inicial. Para Sato e Souza (2001), a pesquisa etnográfica permite acesso aos processos sociais, os quais permitem conjecturas sobre como as pessoas constroem o coletivo, além de que o 
acesso às formações organizacionais formalmente constituídas, que podem ser exploradas com maior proximidade do pesquisador na busca pelas respostas à pesquisa.

\section{Representações sociais, alteridade e deficiência: aportes históricos, conceituais e metodológicos.}

Nossas incursões partem incialmente de traçados históricos, como suporte inicial para o entendimento sobre como foram conduzidas as conotações atribuídas à deficiência. De acordo com Mazzota (2011), a noção de deficiência que prevalecia em meados do século XVIII quase sempre se relacionava a questões ligadas ao ocultismo e misticismo, tal fato fazia com que as pessoas fossem segregadas do convívio social. A própria religião se encarregou de colaborar para esse estigma ao relacionar a perfeição do homem à "imagem e semelhança de Deus": aqueles que não se enquadravam nessa condição eram marginalizados ou sumariamente ignorados.

Nessa percepção primeira, o autor demostra como a discriminação às pessoas que não se enquadravam aos padrões tidos como normais, na época, era legitimado dentro da sociedade, muitas vezes com a colaboração do próprio discurso religioso, que enfatizava as características de perfeição humana, o que corroborava sobremaneira para a disseminação de atitudes segregadoras àqueles que destoassem dessa orientação.

Já no Brasil no início do século XX, temos, de acordo com Maior (2017), a deficiência em discursos que a relacionavam ao modelo biomédico, o qual se justificava por uma concepção de incapacidade, que poderia ser superada; essa condição, para tanto, seria conquistada por meio de processos de reabilitação, de maneira a possibilitar ao sujeito possibilidades de cura, para que posteriormente pudesse ser integrado à sociedade. Essa noção pode ser verificada nos títulos de trabalhos científicos publicados no começo do século XX, documentados por Mazzota (2011, p. 31):

Em 1900 durante o $4^{\circ}$ Congresso Brasileiro de Medicina e Cirurgia no Rio de Janeiro, o Dr. Carlos Eiras apresentou a monografia intitulada $D a$ educação e tratamento médico-pedagógico dos idiotas. Por volta de 1915 foram publicados três outros importantes trabalhos sobre a educação de deficientes mentais: a educação da infância anormal da inteligência no Brasil, de autoria do professor Clementino Quaglio, de São Paulo, e Tratamento e educação das crianças anormais da inteligência e A educação da infância anormal das crianças mentalmente atrasadas na América Latina, obras de Basílio de Magalhães, do Rio de Janeiro. Na década de 1920, o importante livro do professor Norberto de Souza Pinto, de Campinas (SP) Intitulado Infância retardatária. (grifos do autor) 
Nessa perspectiva, o sujeito deficiente é visto como alguém que pode ser tratado dentro de uma condição "anômala" do corpo, algo não aceitável, tendo em vista um padrão que se baseava na noção de corpo saudável. Nesse sentido, a deficiência seria a face do corpo doente, portanto justificar-se-iam os tratamentos dolorosos, a que eram submetidos os sujeitos na busca pelas supostas curas.

Segundo Souza (2016), já na segunda metade do século XX, precisamente na década de 60, a marginalização das pessoas com deficiência prossegue, mas agora direcionada por discursos de normalização e integração que se aliavam a movimentos reivindicadores de maior participação política dos deficientes na sociedade.

Contudo, é importante ressaltar que o próprio significado da palavra integração conspira a uma determinada lógica de segregação, pois “integrar” em seu próprio significado está atrelado a uma noção de adaptação. Adapta-se aquele ou aquilo que por alguma condição não está condizente com parâmetros, de acordo com algum referencial a ser adotado, nesse caso o parâmetro, a saber, seria o social.

Outro ponto a ser tocado refere-se à ideologia que projetou os discursos que incentivavam os programas de integração. Entre as décadas de 60 e 70 tem-se uma série de instabilidades econômicas geradas pela crise do petróleo, o que justifica a conveniência de se adotar por muitos países a filosofia integradora de atendimento aos deficientes, principalmente por conta da economia aos cofres públicos. (MENDES, 2006, p. 388).

A faceta econômica ocultava o discurso de integração, ou seja, muita embora fosse propagado que os deficientes deveriam ser integrados à sociedade, o que de fato acontecia era a utilização dessa justificativa para diminuir os custos com possíveis atendimentos paralelos e assistivos a estes. Nesse período, a instituição escolar passa a ser um dos lugares em que os discursos de integração foram mais efetivados, sem ao menos considerar-se a devida preparação para isso, o que acabou por acentuar discriminação às pessoas: "A política de integração escolar teve como maior impacto o fortalecimento do processo de exclusão na escola pública de crianças consideradas indesejadas pela escola comum" (BUENO apud MENDES, 2006, p. 397)

Esse cenário irá se estender até os idos da década de 1980, quando percepções sobre deficiência passaram a estar entre discursos de inclusão, vale destacar que tal discurso não tem em sua essência a diluição das fronteiras de exclusão, as quais, como podemos observar, historicamente acompanham os discursos relativos ao termo deficiência. Grandes agências internacionais de regulação, como Banco Mundial, Organização das Nações Unidas para Educação, Ciência e Cultura (UNESCO), Fundo das Nações Unidas para Infância (UNICEF) 
e Programa das Nações Unidas para o Desenvolvimento (PNUD), se encarregam de produzir e disseminar marcos regulatórios mundiais para educação, que estão em consonância com os interesses do grande capital, portanto é necessário olhar para tais políticas com olhos de criticidade em virtude de que o termo inclusão também está assentado em uma lógica dicotômica, as reinvenções dos sistemas econômicos se transvestem de políticas assistencialistas para esconder o verdadeiro viés excludente que marca a sociedade do capital.

O norteador Inclusivo que delimita as conduções sobre a deficiência, de acordo com Sousa (2016), se estende pelos anos 2000, ressignificado, para se tornar compatível aos interesses dos sistemas políticos e econômicos, como explanado anteriormente; contudo, é importante frisar a relevância do protagonismo dos grupos sociais que abarcaram a causa, promovendo diversos embates, a fim de definir conquistas sociais e lutar para diminuir as desigualdades. (SOUZA, 2016, p. 369).

As trajetórias acima descritas nos permitem dimensionar, no decurso de uma lógica temporal, como os significados atribuídos ao outro deficiente transitaram por entre misticismos, incapacidades, reabilitações, integrações e inclusões. Dessas concepções, não podem ser desconsiderados contextos históricos, políticos, sociais, culturais que vão dar o pano de fundo necessário à construção das representações sociais ligadas à deficiência de acordo com cada período.

Essas gradações que buscam definições do outro são incorporadas e disseminadas no inconsciente coletivo e influenciam, sobremaneira, as formas como as pressupomos ou mesmo incorporamos. Para Muscovici (1998), são ditas também representações sociais as percepções concernentes ao outro, e se as julgamos verdadeiras ou falsas dependerá sempre de como experimentamos sentimentos a seu respeito, ligadas a referenciais de legitimidade condicionados por nossas visões de mundo.

Destaca-se que é o autor quem inaugura a Teoria das representações sociais dentro do campo da Psicologia Social. Muscovici (2015) explicita que a referida teoria contribuiu para debates relativos às percepções dos fenômenos sociais tal como são, atribuindo ao ambiente físico a responsabilidade por gerar os estímulos responsáveis pelas respostas imbricadas em nossas percepções, ideias e atribuições. As representações seriam o produto desses estímulos, a resposta comum de um determinado grupo na intenção de abarcar os fragmentos formadores de compreensão da realidade, muito embora essa resposta comum seja passível de mudanças.

O conceito das Representações foi assim definido: 
Um sistema de valores, ideias e práticas, com uma dupla função: primeiro, estabelecer uma ordem que possibilitará às pessoas orientar-se em seu mundo material e social e controla-lo; e, em segundo lugar, possibilitar que a comunicação seja possível entre os membros de uma comunidade, fornecendo-lhes um código para nomear e classificar, sem ambiguidade, os vários aspectos de seu mundo e sua história individual e social. (MUSCOVICI, 2015, p. 21)

Ressalta-se sobre a teoria das representações sociais que elas nos são impostas, através de transmissões que se naturalizam no espaço da cotidianidade; elas estão também atreladas aos ajustamentos que nossos sistemas perceptivos e cognitivos sofrem ao longo do tempo, e em diversas gerações, fatores que decerto influenciaram e influenciam em seus formatos (MUSCOVICI, 2015).

As representações sociais seriam nossos primeiros mecanismos de cognição ativados para que possamos realizar nossas leituras do mundo, dentro de certo campo de coerência. Almeida discorre sobre tal necessidade humana, no sentido de que "os indivíduos tendem a classificar os objetos, as pessoas e as situações que servem para situa-lo no mundo" (ALMEIDA, 2005, p. 109)

Outrossim, constata-se que além de serem utilizadas em nível de entendimento coletivos, também abarcam o sentido mais particularizado de compreensão, aqueles que partem do eu em direção a objetos ou pessoas, estes da mesma forma, passam inevitavelmente pelos filtros dos ajustes dos sistemas cognitivos e perceptivos em conformidade com o recorte temporal. A construção das alteridades, influenciadas pelas representações sociais pode ser intendida nessa interface. Corrobora sobre esse aspecto Arruda (1998):

A construção da alteridade e do mesmo se move ao compasso das conjunturas históricas. As mudanças de representações hegemônicas correspondem a novas necessidades coletivas, oriundas da renovação de projetos políticos, econômicos, sociais, de situações culturais e outras. Devem-se a necessidade de estabelecer um novo senso comum a si mesmo e ao outro que de conta ao mesmo tempo da nova situação em que se contemplam e dos novos ângulos que ela ilumina. (ARRUDA, 1998, p. 4142)

Percebemos, assim, que a noção de alteridade não está necessariamente contornada dentro de uma lógica estanque, mas que pode ser fluída e passar por reconstruções assim como são as representações sociais; contudo, a alteridade trata-se de uma forma de compreensão que se delineia na interação com o outro no plano do vínculo social. Nesse sentido Jodelet (1998, p.50) ressalta que a “[...] alteridade não aparece como um tributo que pertenceria à essência do objeto visado, mas sim como uma qualificação que lhe é atribuída do exterior. É um substantivo que se elabora no seio de uma relação social". 
Ademais, tal conceito é de suma importância, como forma de nortear compreensões sobre de que formas as diferenças entre os sujeitos são elaboradas. A conjectura partiria da compreensão de que a oposição entre o eu e o outro só tem sentido em gradações que se iniciam em níveis interpessoais até atingir o estatuto grupal. Assim, a diferença giraria em torno de uma compreensão de que tudo aquilo que é atribuído ao outro está em congruência do que é estranho à própria identidade do eu. (JODELET, 1998)

Se partirmos de uma razão construída de identidade dentro dos moldes de uma concepção de normalidade como padrão constitutivo da sociedade, o que se pode pressupor, a partir de tais explanações sobre a alteridade, é que a diferença estaria assentada então na oposição ao normal, ou seja, o anormal, mas é que relativizado ante a utilização de terminologias como deficiência, que na realidade tem o intuito de apenas criar parâmetros de aceitação.

O grande problema disso está em que tais proposições coexistem e permanecem no espaço da inquestionabilidade, contidas por uma lógica de validação social impedindo o repensar dessa problematização, não permitindo ao outro, atribuído como deficiente, o poder de ser visto fora dessa relação. E é nesse quadro, por conseguinte, que se disseminam conceitos determinantes que influenciarão a posição assumida por esses sujeitos na sociedade.

A fim de verificarmos de que forma são percebidas tais proposituras, dentro do contexto dessa pesquisa, realizamos inicialmente incursões etnográficas, dado que seus pressupostos embasam-se na interação direta com as pessoas e sua vida cotidiana, ajudando a compreender melhor suas concepções, práticas, motivações e os significados que atribuem a essas práticas (CHIZOTTI, 2016, p. 65).

Em seguida optou-se, como método de coleta de dados, entrevistas semiestruturadas, porque partilhamos da noção de Ludke e André (1986, p. 33), segundo os quais "nas entrevistas a relação que se cria é de interação, havendo uma atmosfera de influência recíproca entre quem pergunta e quem responde". Em particular nas entrevistas semiestruturadas não há exigências das questões estruturadas e o entrevistado tem a liberdade de fornecer informações sobre o tema proposto. (LUDKE, ANDRÉ, 1986)

\section{Vila jarana: nos recortes das representações}

A comunidade de Jarana está situada no município de Tijoca, distante aproximadamente $28 \mathrm{~km}$ da cidade de Bragança. Possui aproximadamente 1500 habitantes. São grupos familiares que vivem principalmente da plantação de pequenas roças de cultivo de 
feijão, hortaliças, coco, açaí e principalmente mandioca. Há algumas casas de farinha na Vila, utilizadas entre as famílias em sistema de rotativo, para produção desse produto, o qual é a base principal da alimentação dos moradores. Não há sistema de esgoto ou posto de saúde, contudo há energia elétrica em grande parte das casas e uma pequena escola onde acontecem aulas tanto do Ensino Fundamental quando do Médio: neste nível as aulas ocorrem através do Sistema Modular de Ensino. A escola é o lugar onde grande parte dos jovens estudantes se concentra entre os períodos da manhã e da tarde. O espaço escolar também é frequentado por jovens que vem de comunidades adjacentes à vila Jarana, os quais geralmente vem de moto, ou enfrentando longas caminhadas pelas estradas de terra batida.

A pesquisa foi realizada entre o período do dia 11 de setembro de 2017 a 07 de novembro de 2017, cujos sujeitos foram os próprios estudantes da Vila. Os jovens em questão fazem parte das turmas do $1^{\circ}$ e $3^{\circ}$ ano do Ensino Médio. No Ensino Médio, os jovens estão em uma faixa etária entre 15 a 21 anos, e entre eles há uma aluna que é matriculada como deficiente, além de na própria comunidade existirem pessoas que apesar de não estarem matriculadas na escola também eram apresentadas como deficientes pelos sujeitos da pesquisa.

O contato com os estudantes se deu em momentos em que não estavam ocorrendo as aulas, em encontros informais em frente à escola, lugar para onde estes se dirigiam quando não estavam acontecendo as aulas, ou em visitas às residências dos mesmos, sendo que se mostraram bastante receptivos quanto à participação na pesquisa. Para que fossem exploradas as representações sociais sobre os sujeitos caracterizados pelos estudantes como deficientes, partiu-se de uma questão referência: Para você o que é ser deficiente?

Ao longo do contato com estes, foi sendo delineado um sentido de deficiência, o qual se aproximava da construção de representações sociais corporificadas em um tipo de alteridade, que foi disposta em determinadas categorizações. Nesse sentido, no quadro 1, os sujeitos foram ordenados em numerações que vão 1 a 13, e também estão dispostos os sentidos identificados nas falas dos estudantes, os quais categorizaram o sujeito deficiente (Algumas categorizações que em que estão assentadas as representações). 
Quadro 1 - Categorização das Representações Sociais dos Estudantes

\begin{tabular}{|c|c|}
\hline $\begin{array}{l}\text { Categorizações } \\
\text { representaç̃̃es }\end{array}$ & SUJEITOS \\
\hline Incapaz & $\begin{array}{l}\text { Sujeito } 1 \text { - "Ser deficiente é não poder andar, não ter perna, não ter } \\
\text { braço, andar de cadeira de rodas". } \\
\text { Sujeito } 2 \text { - "É ser diferente. Não ter a capacidade de fazer o que } \\
\text { outras pessoas fazem, por exemplo, uma pessoa que não anda, vê as } \\
\text { pessoas jogando bola, tem vontade e não pode". }\end{array}$ \\
\hline Dependente & 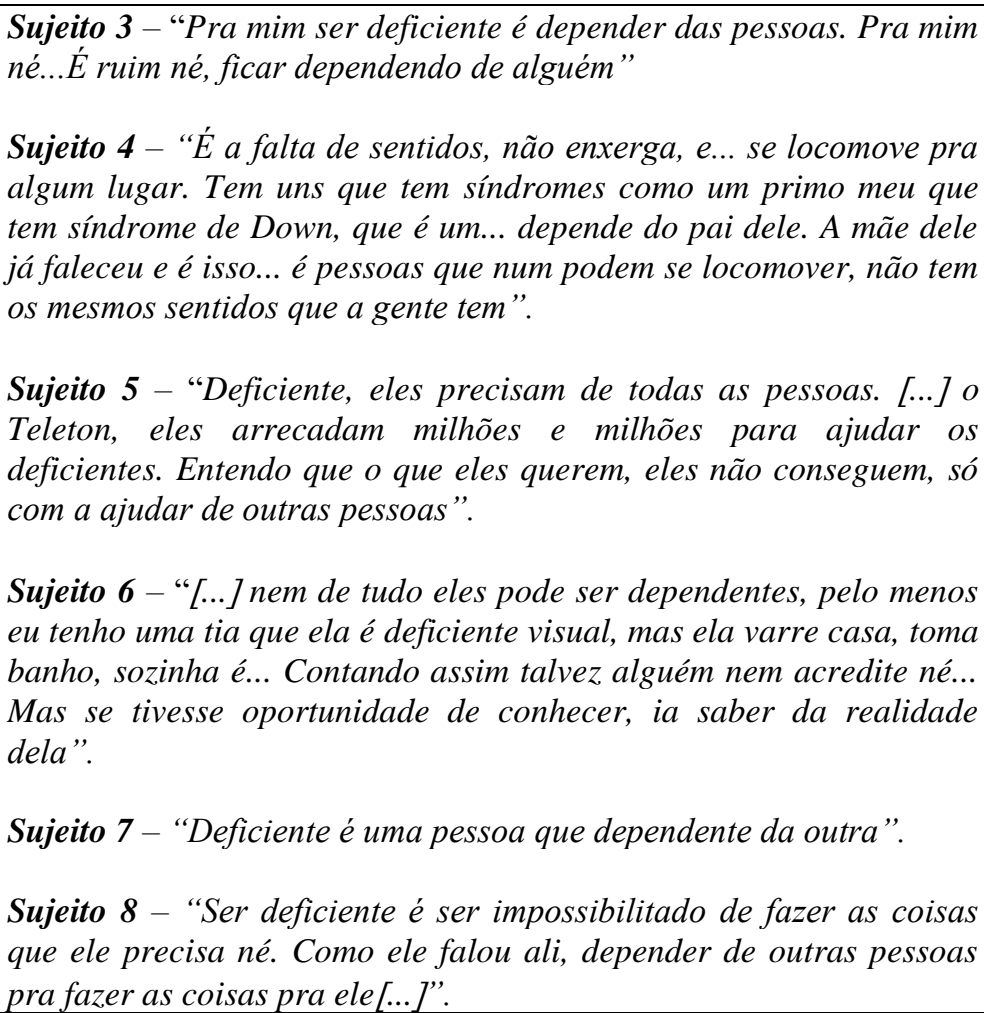 \\
\hline Imperfeito & $\begin{array}{l}\text { Sujeito } 9 \text { - "Ser deficiente é uma maneira de pessoa uma pessoa não } \\
\text { se locomover. [...] se botar pessoa normal e um deficiente, tem várias } \\
\text { diferenças né, porque um é que é perfeito[...] ele só faz alguma coisa } \\
\text { se uma pessoa ajudar eles" }\end{array}$ \\
\hline Indesejável & $\begin{array}{l}\text { Sujeito } 10 \text { - "Ser deficiente é... professora... deixa eu ver... hã...eu } \\
\text { acho que...sei lá... pra gente, que nós somo quase perfeitos, eu acho } \\
\text { que seria indesejável também [...] quase fora da sociedade né." } \\
\text { Sujeito } 11 \text { - "Eu acho que é uma coisa que ninguém deseja, } \\
\text { deficiente eu acho que sofre alguns preconceitos por não ter alguma } \\
\text { das parte funcionando, do corpo funcionando. Muitas vezes não são } \\
\text { chamados pra fazer algum trabalho, ai não tem uma parte do corpo } \\
\text { funcionando. [... Jeu acho qui é ruim... }\end{array}$ \\
\hline Funcionalidade relativa & $\begin{array}{l}\text { Sujeito 12-"Deficiente. Pra mim, pra alguns é bom, agora pras } \\
\text { outros não é, porque a pessoa que é deficiente aprende outras coisas } \\
\text { que não aprenderam quando tinham a parte do corpo humano } \\
\text { funcionando tudo né". }\end{array}$ \\
\hline Doente & $\begin{array}{l}\text { Sujeito } 13 \text { - "É uma doença. É que não pode fazer quase nada. Se eu } \\
\text { fosse cego e não podia enxergar... o que era que eu ia ver? nada! Só } \\
\text { escuridão". }\end{array}$ \\
\hline
\end{tabular}

Fonte: Alunos da comunidade de Vila Jarana - Elaborado pelos autores 
As evidências presentes na tabela foram revelando certos enquadramentos nos quais o outro, sob a alcunha da deficiência, era relevado, na maioria dos casos em perspectivas dicotômicas, assentadas em categorizações cujos parâmetros ressaltavam esses sujeitos à margem do que é considerado "normatizado". De fato, a exposição dos dados corrobora com os apontamentos teóricos. Ao resgatarmos Muscovici (2015), percebemos que a noção de representações sociais está assentada principalmente em funções ligadas à expressão de compreensões que corroboram para trazer sentidos de familiaridade, os quais funcionam como forma de orientação às pessoas em seu mundo material e social, tanto em relação a pessoas quanto a objetos. A grande questão que se percebe a partir das falas é que os processos de compreensão que norteiam o outro na perspectiva da deficiência estão cimentados em sentidos de familiaridade, que se aproximam de adjetivações como: incapaz, dependente, imperfeito, indesejável, não funcional e doente.

A análise permitiu verificar que essas categorizações se encontram dispostas em contraposição a sentidos como: capaz, independente, indesejável, funcional e perfeito. Para Muscovici (1998), as gradações que nutrem a definição do outro se projetam a partir de espaços de designação, nos quais o parâmetro referenciador é o próprio eu, e no momento em que se cria a noção de gradação ou separação entre o eu e o outro, objetivada pelo sentido de categorizações, esses espaços de designação são nutridos por categorias, as quais são discernidas, em consulta prévia às representações sociais, pois estas se incumbem de costurar os tecidos sociais, inclusive os que irão margear a própria concepção de deficiência na sociedade: este mecanismo age em torno de um sistema de ciclo que tanto alimenta uma alteridade moldada em sentido segregador, quanto permite a conservabilidade das representações que geram esse mecanismo.

Dessa forma, as referências de representação que estão moldando as alteridades coadunam-se em sentidos bifurcados, que se encarregam de ditar o ser do outro, contudo não por ele mesmo, mas na distorção do ser de fato, e dentro desta visão é que será determinada a ordem semeadora de papéis sociais que acabam por naturalizar essa realidade.

Isso irá balizar, no âmbito da intersubjetividade, a validação das representações sociais que permearão a interface entre o eu e o outro, ou seja, na perspectiva da alteridade, podemos dizer que as categorizações que foram desencadeadas pelas representações dos estudantes nos deram indícios para saber como os desenhos da alteridade em torno da deficiência estão ganhando seus contornos naquela comunidade. Jodelet (1998) corrobora com essa questão, pois explica que a alteridade pode atuar como patamares que podem implicar diretamente na forma com estão se evidenciando as relações com o outro; tal reflexão nos ajuda a entender, 
por conseguinte, que tipo de gradações foram assumidas, em grande parte da fala dos estudantes, que basicamente refletem de fato uma clara linha de diferenciação em relação aquele classificado como deficiente.

Uma vez que concordamos que o entendimento do outro passa a ter suas compreensões a partir do eu, isso implica dizer que as representações sociais, nessa perspectiva, funcionam como uma espécie de parâmetro de ajuste social o qual o eu sempre recorrerá para nortear suas práticas e relações sociais com o outro: cabe ressaltar que a alteridade decorrente desse sistema não é determinada pela essência do outro, mas por atribuições advindas do meio social, o qual leva-nos a crer que também é influenciada por diversos outros fatores, que circundam esses espaços e que não foram abordados no contexto pesquisa, mas que podem ser desenvolvidos em estudos futuros que visem explorar como a influência de outros fatores, que gravitam no meio social, podem vir a influenciar na definição das representações sociais assumidas pelos mais diversos grupos de indivíduos.

É relevante ressaltar nas falas dos participantes que a maior parte destes, especificamente, seis participantes, sugeriram em suas falas que o sujeito considerado deficiente encontra-se dentro de uma relação de dependência, o que nos dá a ideia da propagação entre os jovens de certa generalização que representa o outro deficiente, encerrando-o a um corpo, que tanto pode ser dependente em sua totalidade, "Pra mim ser deficiente é depender das pessoas", "Deficiente é uma pessoa que dependente da outra", como observado nas falas dos sujeitos 3 e 7, quanto pode-se acreditar até mesmo em um certo grau de independência, como visto no trecho referente à fala do sujeito 6, "[...] pelo menos eu tenho uma tia que ela é deficiente visual, mas ela varre casa, toma banho sozinha, é...”, porém, atrelada a um sentindo, decerto relativo, ou seja, mesmo que se fale em certa autonomia, esta não está isenta da crença, a qual tem como ponto de partida a ideia de dependência , “[...] nem de tudo eles pode ser dependentes”, tal constatação nos dá indícios de que os sujeitos aos quais se faz referência não tem chances de serem vistos no exterior dessa classificação.

Da mesma forma chamamos atenção para outra relativização, acompanhada no trecho, - "Deficiente. Pra mim, pra alguns é bom, agora pras outros não é, porque a pessoa que é deficiente aprende outras coisas que não aprenderam quando tinham a parte do corpo humano funcionando tudo né”, pois apesar do estudante acreditar ser possível ao deficiente outras possibilidades de aprendizado, ainda permanece a concepção que limita o corpo à correspondência direta com seu viés funcional, o que no caso aproximaria a concepção do corpo deficiente a uma condição anômala, algo já discutido anteriormente, ou seja, o outro 
deficiente acaba sendo reduzido a uma noção que pode ser tida como a face doente de um corpo saudável.

É necessário assimilar que o lugar de fala dos sujeitos está localizado no nível das interações sociais, portanto, uma das implicações desse fato, segundo a própria Jodelet (2013), é que existe uma tendência de fraturar o meio social em categorias, e o palmo que delimita essa fragmentação está contido nas formas pelas quais percebemos o outro dentro de uma lógica de semelhança ou de diferença com o grupo social a qual pertencemos. Essa interface, portanto, pode ser uma via de mão dupla, em que tanto podem ser construídas aproximações com aqueles com os quais nos identificamos quanto à rejeição àqueles que, em nosso âmbito de construção intersubjetiva, não encontram parâmetros de similaridade: é nesse terreno que se espraia a exclusão. A compreensão dessa forma de construção é denomina pela autora como "estereótipos de deslegitimação", que por vezes são usados para segregar determinados grupos pelo entendimento de que não se adequam ao campo de normas e valores aceitáveis. (2013, p. 66)

A propósito de tais inferências deslegitimadoras, Skliar (1999) apregoa que estas não se tratam das pessoas de fato, mas partem de invenções, criadas na sociedade, e que pretensamente têm a intensão de representar o outro, mas que só encontram significado em fronteiras da exclusão, as quais só encontram sentido para o outro deficiente em um regime de verdade, que parece ter como única função a confirmação de nossa pretensa normalidade, capacidade ou perfeição.

Os olhares nesse sentido se voltam para contornos de significações do outro deficiente que são convalidados pelos sujeitos, por meio das representações sociais, que se delineiam em visões que se voltam para e não através dos sujeitos. $\mathrm{O}$ eu que se finca no posto de centro de referência na distinção do outro, ao não se permitir o deslocamento desse eixo, ao menos a um nível de empatia, com olhares mais prologados até mesmo para as relações que estão pacificando para com esses sujeitos no cotidiano, acabam por contribuir para a edificação de caminhos tortuosos para aqueles que têm que lidar concretamente com designações que de fato não os representam em essência; nessa contenda, a própria vida se torna uma luta constante por uma necessidade de ressignificar a lógica em que está cimentada a representações que permeiam as alteridades do outro na perspectiva da deficiência.

\section{Ponderações que não se encerram em pretensões finais}


$\mathrm{Na}$ discussão da relação entre as representações sociais e a alteridade do outro na perspectiva da deficiência é necessário ressaltar que não se pode desconsiderar o trajeto histórico pelo qual vem se desenhando tal relação, trajeto esse em que se mudam os atores e o período, mas onde a lógica que a permeia parece estar apenas a se reajustar, para permanecer nas mesmas conformações sem que de fato se mude os sentidos que a embasa.

Como supõe Skillar (1999), é necessário analisar os discursos que pautam a deficiência para refletir o que vem sendo entendido como norma que se julgar na incumbência de inventar corpos e mentes. Nesse sentido, pudemos compreender que as representações de alteridade que perpassam as concepções de deficiência dos sujeitos da Vila Jarana estão em consonância com os discursos, que pensam a deficiência a partir de representações que inventam sujeitos, estigmatizados pela deficiência, sem que nos fosse possível perceber indicadores que deixem claro outras possibilidades dentro desta relação.

As falas dos sujeitos deixam claro que pensar as representações sociais dos outros sobre a égide da deficiência é pensar sempre com base em uma região limítrofe e invisível, que delimita categorias entre o eu e o outro, mas esse outro a partir das falas dos sujeitos é representado sempre levando-se em consideração categorias, nas quais este está posicionado do outro lado da fronteira, aquele que não se aproxima do eu, ou seja, que não se enquadra ao padrão dominante de uma representação que tem se firmado como hegemônica da deficiência.

Portanto, corroboramos que conhecer a forma como tais discursos estão sendo pacificados é de suma relevância até mesmo para propor reflexões inquietantes que refutem o paradigma em que estão sendo estabelecidas as representações que estão substanciando a alteridade que se observa pelas lentas da deficiência. Se essas reflexões de alguma forma forem provocadas, então podemos dizer que foram atingidos propósitos que não se encerraram no objetivo principal deste trabalho.

A pesquisa foi desenvolvida de maneira a mostrar que pensar a alteridade é adentrar no campo da subjetividade que se expressa na relação com o outro, e entender como são fiados seus mecanismos, em consonância com as representações sociais, bem como estes se expressam na concretude das ações para com o outro em posição de deficiência na sociedade: somente este repensar é capaz de transcender os paradigmas modernos entre o eu e o outro, para além de simples categorizações como normalidade/anormalidade, capacidade/incapacidade, deficiência/eficiência, e quem sabe talvez transcendê-los.

Tais paradigmas devem ser descontruídos, pois na medida em que se encontram acabam por dar continuidade a ciclos arraigados em velhas concepções pacificadas do outro, o 
que irá exigir esforços direcionados a um novo olhar para este outro, que por vezes é fragmentado, penalizado pelo sectarismo de nossas distorções.

\section{REFERÊNCIAS}

ALMEIDA. A. M. O. A Era da cognição Social. In: SANTOS. M. F. S.; ALMEIDA. L. M (orgs). Diálogos com a teoria das representações sociais. Editora Universitária da UFPE, 2005.

ALMEIDA. G. J. As Representações Sociais, o Imaginário e a Construção Social da Realidade. In: SANTOS. M. F. S.; ALMEIDA. L. M (orgs). Diálogos com a teoria das representações sociais. Editora Universitária da UFPE, 2005.

ARRUDA, A. Representando a Alteridade. In: JODELET, D. A alteridade como produto e processo psicossocial. Rio de Janeiro: Ed. Vozes, 2002. p. 48-51.

BRANDÃO, C. R. Identidade e etnia. São Paulo: Ed. Brasiliense, 1986. Disponível em: http://pepsic.bvsalud.org/scielo.php?script=sci_arttext\&pid=S1678-51771994000100002. Acesso em: 28 jul. 2018.

CHIZOTTI, A. Pesquisa qualitativa em ciências humanas e sociais. 6 ed. Petrópolis: Vozes., 2014.

GIL, A. C. Métodos e técnicas de pesquisa social. São Paulo: Atlas, 2008.

JODELET, D. Alteridade como produto e processo psicossocial, In: ARRUDA, A. (org). Representando a alteridade. $2^{\mathrm{a}}$ edição. Petrópolis: Editora Vozes, 2013.

JODELET, D. Os processos Psicossociais da Exclusão. In: SAWAIA, B. (org). As artimanhas da Exclusão: analise psicossocial e ética da desigualdade social. 13 ed. Petrópolis: RJ. Editora Vozes, 2013.

MAIOR, I. História, conceito e tipos de deficiência. Portal do Governo do Estado de São Paulo. Disponível em:

http://violenciaedeficiencia.sedpcd.sp.gov.br/pdf/textosApoio/Texto1.pdf. Acesso em: 12 abr. 2018.

MAZZOTA, M. J. S. Educação Especial no Brasil: história e políticas públicas. 6 ed. São Paulo: Cortez, 2011.

MUSCOVICI. S. Representando a Alteridade, In: Arruda, A. (org). Representando a alteridade. 2 ed. Petrópolis: Editora Vozes, 1998.

MUSCOVICI. S. Representações sociais. Investigação em Psicologia Social. 11 ed. Rio de Janeiro, 2015.

PEIRANO, M. Etnografia, ou a teoria vivida. Ponto Urbe. 2008. Disponível em: file://C:/Users/pc/Downloads/pontourbe-1890.pdf. Acesso em: 16 abr. 2018. 
SATO, L.; SOUZA, M. P. R. Contribuindo para desvelar a complexidade do cotidiano através da pesquisa etnográfica em Psicologia. Disponível em:

http://www.revistas.usp.br/psicousp/article/view/63371/66114. Acesso em: 29 mar. 2018.

SOUZA, S. B. Deficiência: A trajetória de uma concepção. Journal of Research in Special Educational Needs, v. 16, n. 1, p. 366-370, 2016.

SKLIAR, C. A invenção e Exclusão da Alteridade "deficiente" a partir dos significados da normalidade. Educação \& Realidade. v. 24, n. 2, p. 15 - 32, 1999. Disponível em:

http://seer.ufrgs.br/index.php/educacaoerealidade/article/view/55373. Acesso em: 29 de mar. 2018.

\section{Como referenciar este artigo}

PEREIRA, Viviane Silva.; PEREIRA, Ricardo Augusto Gomes.; PAIXÃO, Carlos Jorge. Deficiência em perspectiva: relações entre representações sociais e alteridade na comunidade do Jarana no município de Bragança-PA. Doxa: Rev. Bras. Psico. e Educ., Araraquara, v. 20, n. 2, p. 179-195, jul./dez., 2018. e-ISSN: 2594-8385. DOI: 10.30715/doxa.v20i2.12021

Submetido em: 10/07/2018

Aprovado em: 12/09/2018 